\title{
Muir-Torre syndrome: a variant of the cancer family syndrome
}

\author{
Nigel R Hall, M Angela T Williams, Victoria A Murday, Julia A Newton, D Timothy \\ Bishop
}

\begin{abstract}
Muir-Torre syndrome is characterised by the association of sebaceous tumours of the skin with internal malignancy. In many instances there is a strong family history of cancer and the autosomal dominant mode of inheritance, tumour spectrum, and high incidence of synchronous and metachronous tumours show parallels with the cancer family syndrome or Lynch II syndrome. We report a five generation family with at least two persons displaying the Muir-Torre phenotype, while many other family members have had tumours consistent with cancer family syndrome. The majority of tumours are gastrointestinal, gynaecological, and urological, with several persons having multiple primaries. The prognosis appears to be better than would be expected. Sebaceous tumours are a marker for internal malignancy and should prompt a search for occult cancer in the individual person and family members. In documented Muir-Torre families, at risk persons should be entered into screening programmes similar to those used in the Lynch II syndrome.
\end{abstract}

( $(\mathcal{F}$ Med Genet 1994;31:627-631)

In 1967 Muir et al ${ }^{1}$ described a subject with multiple sebaceous adenomas and keratoacanthomas of the face who developed squamous cell carcinoma of the larynx, four synchronous colorectal adenocarcinomas, three colorectal polyps, and two duodenal carcinomas over a six year period. The following year Torre ${ }^{2}$ independently reported a man with multiple sebaceous tumours in association with ampullary and colonic cancer. Neither of these reports documented family members with the same syndrome. Rulon and Helwig ${ }^{3}$ reported two cases where there were relatives with a variety of cancers and others also found affected family members. ${ }^{45}$ The significance of this was not fully appreciated until Anderson described a large pedigree ${ }^{6}$; subsequently, Lynch et $a l^{8}$ proposed that the Muir-Torre phenotype might be a more florid expression of the Lynch II or cancer family syndrome. Indeed, one of the cases Lynch described was found to be a descendant of Warthin's family $G$, which is considered to be the first description of the familial cancer syndrome now termed "Lynch II".9

Following numerous case reports, the MuirTorre syndrome (McKusick No 158320) ${ }^{10}$ has become a well documented cancer associated genodermatosis. The typical skin tumours include sebaceous adenomas, epitheliomas, and carcinomas; keratoacanthomas and basal cell carcinomas with sebaceous differentiation also occur. ${ }^{11}$ The spectrum of internal malignancies is wide, with colorectal carcinomas accounting for about half the cancer diagnoses. Other tumours include transitional cell tumours of the renal tract, carcinomas of the endometrium, ovary, breast, upper gastrointestinal tract (including duodenum), and laryngeal tumours. There is a high incidence of synchronous and metachronous disease, but despite this the tumours may be relatively indolent and the prognosis is often favourable. ${ }^{12}$ At least threequarters of the reported cases of Muir-Torre syndrome also document a family history, ${ }^{13}$ though it is of note that the expression of the skin lesions may only be seen in a minority of the family members. ${ }^{8}$ We report here a large family from the West Midlands region to characterise further the familial aspects of the syndrome.

\section{Description of the family}

PEDIGREE

The proband was referred because he had multiple primary carcinomas and a strong family history of cancer. Twenty one family members were contacted after consent was obtained from their general practitioners and hospital consultants, and a detailed medical history was taken in order to construct the pedigree (figure). All diagnoses were confirmed where possible from hospital notes, pathology records, or death certificates (table 1 ). We have been able to verify skin lesions typical of the Muir-Torre syndrome in only two persons (IV·12 and IV·14), though other family members have had skin lesions, some of which were excised but not sent for histological analysis.

\section{TUMOUR CHARACTERISTICS}

Eleven verified colorectal carcinomas were found in seven family members. On three occasions synchronous carcinomas were present (IV.12, twice in IV.15), and a synchronous adenoma was found in one further person (IV-2). One member (IV-15) had two metachronous lesions, and another (IV-2) developed an anastomotic recurrence nine years after her first primary. The median age of onset for the first colorectal tumour was 47 , and six of the seven $(86 \%)$ were in the right colon. Nine of the tumours had breached the bowel wall and there was lymph node involvement in at least five. Five tumours showed mucinous histology and six were poorly differentiated (table 2 ). 


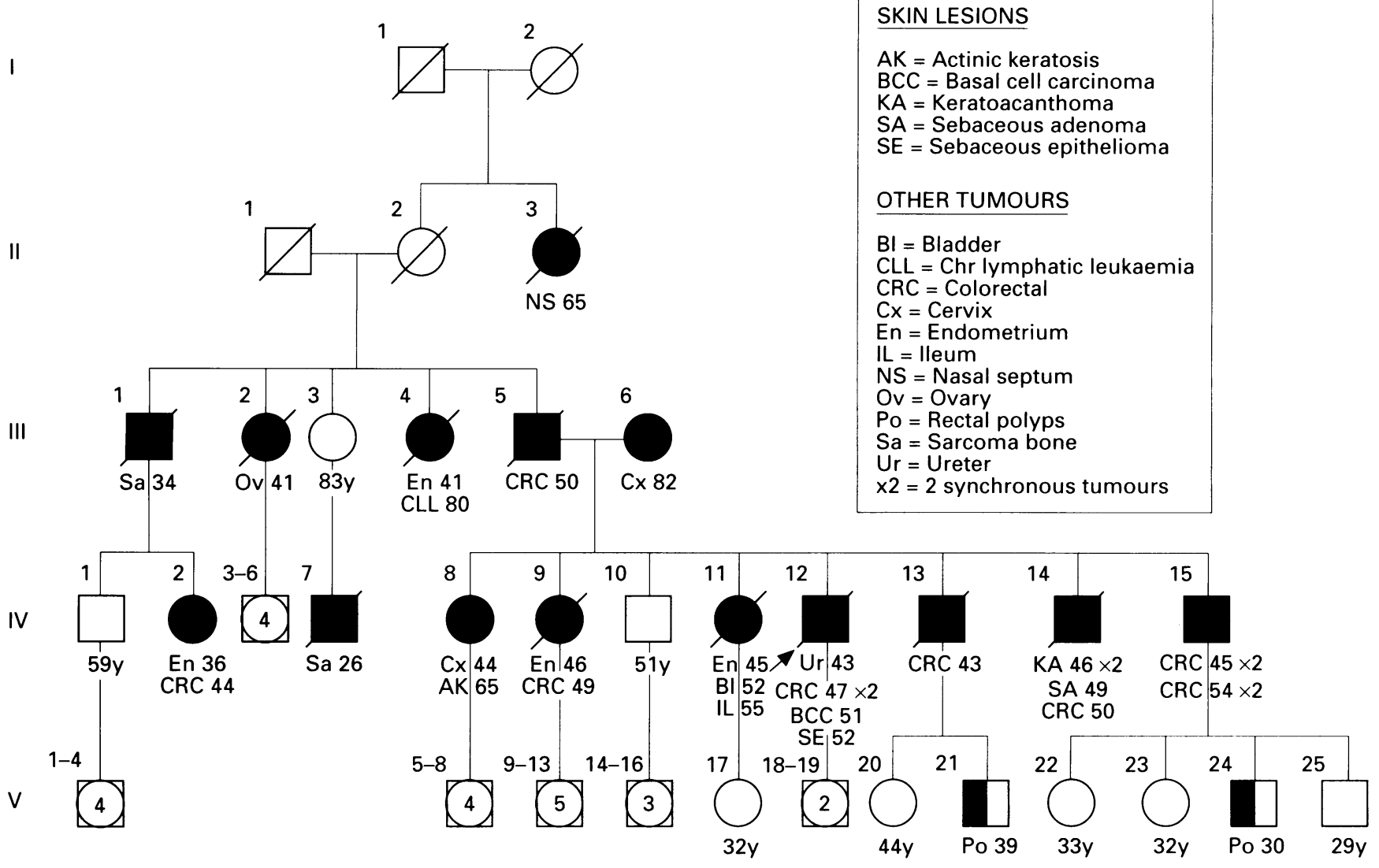

Pedigree showing skin lesions and cancer diagnosis in family members. Verified cancer diagnoses are shown by full shading and the two subjects with polyps by half shading. Under each symbol is listed the diagnosis (see key for abbreviations) and age at diagnosis. For unaffected members the current age or age at death are shown.

Table 1 Tumour registry showing details of documented tumours in family members including site and age at diagnosis (method of confirmation)

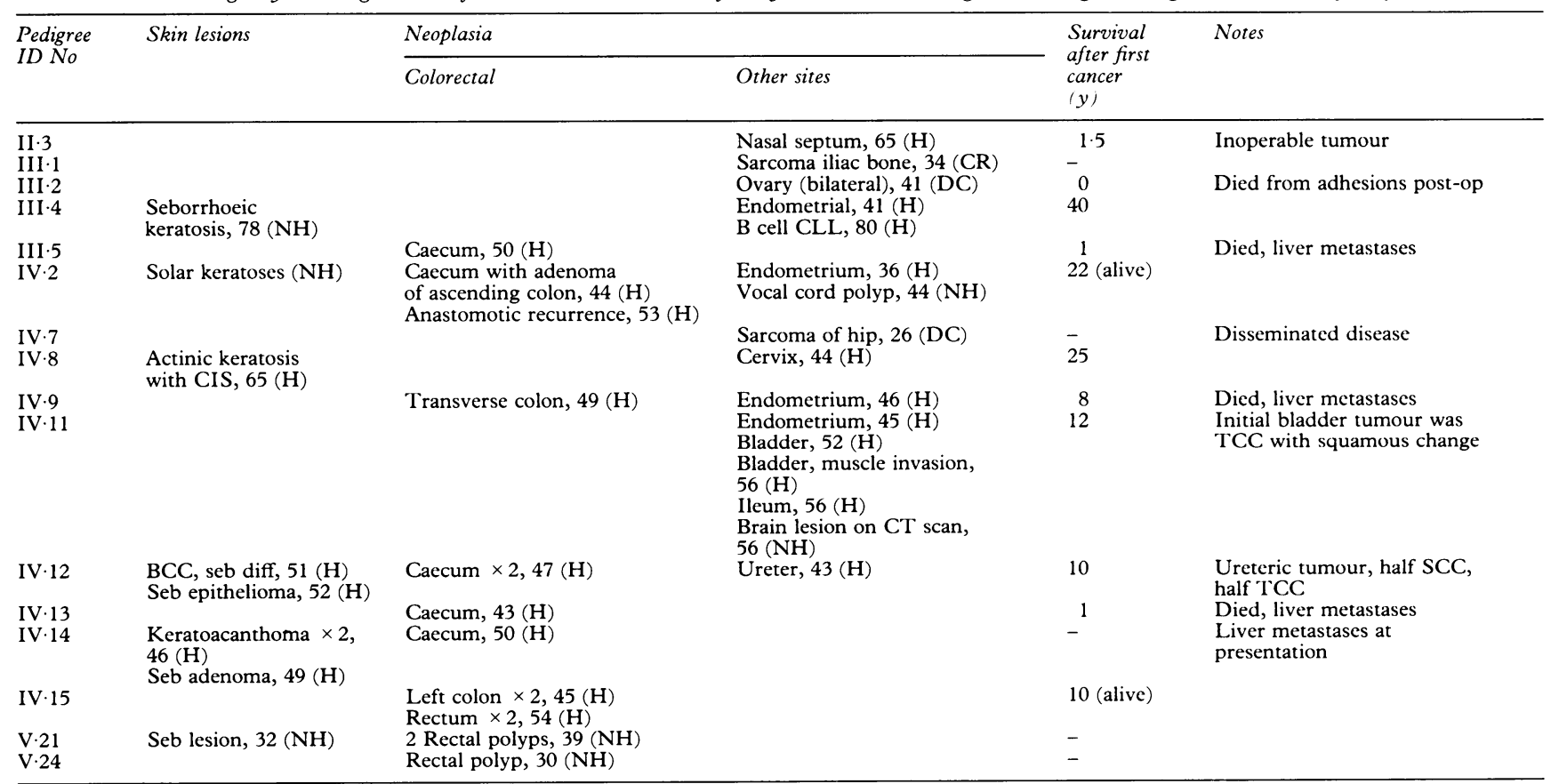

Confirmation: $\mathrm{H}=$ histology, $\mathrm{CR}=$ cancer registry, $\mathrm{DC}=$ death certificate, $\mathrm{NH}=$ no histological confirmation

Other abbreviations: $\mathrm{BCC}=$ basal cell carcinoma, $\mathrm{CIS}=$ carcinoma in situ, $\mathrm{SCC}=$ squamous cell carcinoma, $\mathrm{Seb}=\mathrm{sebaceous}$, $\mathrm{TCC}=\mathrm{transitional}$ cell carcinoma $\times 2=$ two synchronous tumours. 
Table 2 Pathological details of 11 colorectal cancers in seven family members. A dash incidates that there is no specific comment in the histology report

\begin{tabular}{|c|c|c|c|c|c|c|c|}
\hline $\begin{array}{l}\text { Pedigree } \\
\text { ID No }\end{array}$ & $\begin{array}{l}\text { Site of } \\
\text { cancer }\end{array}$ & $\begin{array}{l}\text { Gross } \\
\text { appearance }\end{array}$ & $\begin{array}{l}\text { Size } \\
(\mathrm{cm})\end{array}$ & $\begin{array}{l}\text { Invasion } \\
\text { through } \\
\text { wall }\end{array}$ & $\begin{array}{l}\text { Involvement } \\
\text { of lymph } \\
\text { nodes }\end{array}$ & $\begin{array}{l}\text { Mucinous } \\
\text { histology }\end{array}$ & $\begin{array}{l}\text { Degree of } \\
\text { differentiation }\end{array}$ \\
\hline III. 5 & Caecum & - & - & Yes & - & - & Poor \\
\hline IV 2 & Caecum & Ulcerating & 5 & Yes & No & - & Anaplastic \\
\hline IV 9 & $\begin{array}{l}\text { Transverse } \\
\text { colon }\end{array}$ & Annular & 4 & Yes & Yes & - & Poor \\
\hline \multirow[t]{2}{*}{ IV $\cdot 12$} & Caecum & Ulcerating & $6.5 \times 5$ & Yes & Yes & Focally & Well \\
\hline & Caecum & Discoid & $3.5 \times 3$ & Yes & Yes & Predominantly & - \\
\hline IV $\cdot 13$ & Caecum & $\begin{array}{l}\text { Annular, } \\
\text { ulcerating }\end{array}$ & 5 & Yes & Yes & Focally & Poor \\
\hline \multirow{5}{*}{ IV 15} & Caecum & Ulcerating & - & Yes & Yes & Focally & Poor \\
\hline & Left colon & Annular & 3 & Yes & - & & Moderate \\
\hline & Left colon & Polyp & 1 & No & - & Predominantly & \\
\hline & Rectum & Annular & 2.5 & Yes & No & - & Poor \\
\hline & Rectum & Polyp & - & No & No & - & Moderate \\
\hline
\end{tabular}

Four females had endometrial carcinoma, all under the age of 47 , and for each this tumour was their first malignancy. Other female genital tract tumours included a bilateral ovarian cancer and a cervical cancer.

\section{PROGNOSIS}

Prolonged survival is evident in IV.2 who had endometrial and colorectal primaries and a recurrent colonic carcinoma but remains alive after 22 years, in IV. 12 who had five tumours over seven years with liver metastases and subcutaneous lumps for nearly two years, and still maintained a fair standard of health until his death 10 years after his first cancer was diagnosed, in IV.11 who had tumours at three different sites over nine years and survived a further three years, and IV.15 who had two colorectal resections for synchronous cancers and is alive 10 years later. In contrast, a number of family members had a very poor prognosis owing to the inoperability of their tumour or the presence of metastatic disease at presentation.

\section{Discussion}

The inheritance of cancer susceptibility in this family is consistent with dominant inheritance but with apparent oversegregation. This may well be because of ascertainment and chance, though it should also be recognised that some cancers may not result from genetic susceptibility. This situation is becoming clearer after our recent demonstration of linkage in this family, and a second Muir-Torre family, to the same locus $^{14}$ on chromosome $2 p$ that has been reported for the Lynch II syndrome. ${ }^{15}$ It thus appears that Muir-Torre and Lynch II are allelic, providing support to the findings of other groups ${ }^{6-816-18}$ that the Muir-Torre syndrome is often associated with a significant family history and moreover that it represents a phenotypic variant of the cancer family syndrome. Our haplotype analysis of the pedigree shows that the persons with colorectal or endometrial cancer (with or without sebaceous lesions) share the same segment of $2 p$ at this locus, consistent with the view that these two cancer sites are characteristic of the syndrome (manuscript in preparation).
While the majority of other tumours seen in the family have been described in familial syndromes, two tumour sites deserve mention. First, there are two cases of bone sarcomas in this family. Sarcomas have been reported in both Muir-Torre ${ }^{3}$ and cancer family syndrome, ${ }^{19}$ but they are very infrequent. Nevertheless, the finding of two bone sarcomas at young ages in relatives in this cancer family is suggestive that they may arise because of a common inherited susceptibility, especially since one sarcoma occurred in an obligate gene carrier (III-1). Preliminary linkage analysis suggests, however, that the mother of the second sarcoma case (IV.7) has not inherited the "disease" haplotype. These discrepant findings do not, therefore, clarify the situation of sarcoma in the Muir-Torre syndrome. Second, IV· 8 has a cervical carcinoma, a malignancy which is usually regarded as having a viral rather than inherited aetiology. Lynch et $a l^{B}$ reported three cases of cervical cancer in a Muir-Torre family, yet in none was there any other skin lesion or cancer typical of the syndrome, nor evidence for being a gene carrier, and they questioned the significance of this tumour. As IV-8 does not share the "disease" haplotype, this casts further doubt that cervical cancer is part of the Muir-Torre syndrome. Further molecular genetic investigation of additional families will be required to answer the question of precisely which tumours fall into the syndrome and which arise by chance.

Only two affected persons in this family had skin lesions histologically proven to be consistent with those seen in Muir-Torre syndrome, though others may also show the phenotype. This finding is in keeping with other reports of incomplete expression of the skin features in some members. ${ }^{781820}$ The skin lesions were not as florid as are frequently described and this indicates the importance of careful examination of the skin in those persons who have had cancer at a young age, more than one internal malignancy, or who have a family history of malignancy. Seborrhoeic keratosis and actinic keratosis have been listed in the tumour registry, though they are not recognised as features of the Muir-Torre syndrome: we list them for completeness rather than because we feel they represent the Muir-Torre phenotype.

The sebaceous gland tumours seen in the 
Muir-Torre syndrome are rare in the general population. Over a 60 year period at the Mayo Clinic, only 59 cases of sebaceous adenoma, epithelioma, or carcinoma were biopsied. ${ }^{11}$ Strikingly, in 25 of these ( $42 \%$ ) there was found to be one or more associated internal malignancies, thus fulfilling the criteria for the MuirTorre syndrome. All but seven of these cases had a family history of malignancy and a family history of cancer was found in four additional patients with skin lesions but no internal malignancy. ${ }^{11}$ Thus a sebaceous tumour appears to be a marker for the Muir-Torre syndrome and the finding of a lesion should prompt a thorough search for an occult malignancy. ${ }^{21}$ However, the temporal association of skin lesions with internal malignancy is inconstant, with $28 \%$ of lesions appearing before, $12 \%$ concurrently with, and $59 \%$ after diagnosis of the first malignancy. ${ }^{12}$ If a malignancy is not found at presentation of the skin lesion then it would seem prudent to enter the patient into a long term surveillance programme.

The spectrum of remaining tumours in this family, their characteristics, and age of onset are similar to those seen in the Lynch II syndrome. ${ }^{19}$ The colorectal cancers occurred at young age and showed a striking right sided predominance. Moreover, the occurrence of a small bowel cancer in IV 11 and a ureteric cancer in IV 12 , both very rare in the general population, are characteristic of the Lynch II phenotype. ${ }^{22-25}$

The most peculiar feature of the Muir-Torre syndrome is the apparently indolent course of the cancers and the resulting relatively good prognosis. While no studies have directly addressed this phenomenon, a retrospective review of 120 persons showing the Muir-Torre phenotype estimated the median survival after first diagnosis of malignancy to be 12 years. ${ }^{12}$ Comparing this with a five year survival from colorectal cancer in the general population of only $35 \%{ }^{26}$ the prolonged survival is notable. Given that collection of pedigree information is facilitated in families where there are more surviving affected members, the apparently improved prognosis may be at least partly explained by an unquantifiable bias in ascertainment. Even harder to explain is the relatively late stage of presentation of the colorectal tumours, with a high proportion of mucinous and poorly differentiated tumours, all of which are generally associated with a poor prognosis. ${ }^{2728}$ Mecklin et $a l^{29}$ noted features of mucinous tumours and poor differentiation in the cancer family syndrome, but the same workers did not find improved survival in their series. ${ }^{30}$ Lynch has shown improved survival in his cancer families, ${ }^{3132}$ but this is not as striking as in Muir-Torre patients.

The high incidence of malignancy in these families makes a very strong case for screening in members likely to be at risk of developing cancer or colorectal polyps. To screen for malignancy in all of the wide spectrum of potential sites, however, would produce a cumbersome and impracticable programme. Screening protocols should be based on those commonly in place for Lynch II families, with concentration on the colorectum, female genital tract, and possibly the renal tract. In some families, the occurrence of certain other tumours would be an indication for additional screening modalities, for example, upper gastrointestinal endoscopy for stomach cancer. Published screening recommendations, however, are scanty and vary considerably between centres. ${ }^{1233-36}$ While colorectal screening is well established, the efficacy of pelvic and urological surveillance has yet to be proven. In addition, regular skin examination, advice to bring even minor symptoms to the notice of the family practitioner, and careful genetic counselling should ensure that all family members understand the need for screening and are kept under close review.

We are indebted to the many consultants, general practitioners, pathologists, and cancer registries who have provided the clinica information required to formulate this report, as well as the family members themselves. In particular, our thanks go to D A D Chetiyawardana (Queen Elizabeth Hospital, Birmingham) Mr K D Fortes Mayer (Manor Hospital, Walsall), and Dr E Conway-McGee (Galway, Eire).

1 Muir EG, Yates Bell AJ, Barlow KA. Multiple primary carcinomata of the colon, duodenum, and larynx associated with kerato-acanthomata of the face. Br f Surg 1967; 54:191-5.

2 Torre D. Multiple sebaceous tumours. Arch Dermatol 1968;98:549-51.

3 Rulon DB, Helwig EB. Multiple sebaceous neoplasms of the skin: an association with multiple visceral carcinomas, skin: an association with multiple visceral carcinomas,

4 Jakobiec FA. Sebaceous adenoma of the eyelid and visceral malignancy. Am ₹ Ophthalmol 1974;78:952-60.

5 Reiffers J, Laugier P, Hunziker N. Hyperlasies sébaceés, kérato-acanthomes, épithéliomas du visage et cancer du côlon. Dermatologica 1976;153:23-33.

6 Anderson DE. An inherited form of large bowel cancer: Muir's syndrome. Cancer 1980;45:1103-7.

7 Lynch HT, Lynch PM, Pester J, Fusaro RM. The cancer family syndrome: rare cutaneous phenotypic linkage of Torre's syndrome. Arch Intern Med 1981;141:607-11

8 Lynch HT, Fusaro RM, Roberts L, Voorhees GJ, Lynch JF. Muir-Torre syndrome in several members of a family with a variant of the cancer family syndrome. $\mathrm{Br} \mathcal{f}$ Dermatol 1985;113:295-301.

9 Warthin AS. Heredity with reference to carcinoma. Arch Intern Med 1913;12:546-55.

10 McKusick VA. Mendelian inheritance in man. 10th ed. Baltimore: The Johns Hopkins University Press, 1992.

11 Finan MC, Connolly SM. Sebaceous gland tumors and systemic disease: a clinicopathologic analysis. Medicine systemic disease: a clinicopath
(Baltimore) 1984;63:232-42.

12 Cohen PR, Kohn SR, Kurzrock R. Association of sebaceous gland tumours and internal malignancy: the Muir-Torre syndrome. Am f Med 1991;90:606-13.

13 Schwartz RA, Goldberg DJ, Mahmood F, et al. The MuirTorre syndrome: a disease of sebaceous and colonic neoplasms. Dermatologica 1989;178:23-8.

14 Peltomäki P, Aaltonen LA, Sistonen P, et al. Genetic mapping of a locus predisposing to human colorectal cancer. Science 1993;260:810-12.

15 Hall NR, Murday VA, Chapman P, et al. Genetic linkage in Muir-Torre syndrome to the same chromosomal site as cancer family syndrome. Eur f Cancer 1994;30A:180-2.

16 Shapiro C, Christiansen N, Fretzin D, Evans R, Ross D. Muir-Torre syndrome. F Surg Oncol 1986;31:160-2.

17 Cruz Vigo F, Pardo R, Saenz D, Fernandez T, Leiva $O$ Muir-Torre syndrome with multiple neoplasia. $\mathrm{Br}$ f Surg 1992;79:1161.

$18 \mathrm{Li} \mathrm{FP,} \mathrm{Eng} \mathrm{C.} \mathrm{The} \mathrm{familial} \mathrm{Muir-Torre} \mathrm{syndrome.} \mathrm{Ann}$ Intern Med 1993;119:539.

19 Mecklin J-P, Järvinen HJ. Tumor spectrum in cancer family syndrome (hereditary nonpolyposis colorectal cancer). Cancer 1991:68:1109-12.

20 Banse-Kupin L, Morales A, Barlow M. Torre's syndrome: report of two cases and review of the literature. $\mathcal{F}$ Am Acad Dermatol 1984;10:803-17.

21 Rothenberg J, Lambert WC, Vail JT Jr, Nemlick AS Schwartz RA. The Muir-Torre (Torre's) syndrome: the significance of a solitary sebaceous tumor. $\mathcal{f} \mathrm{Am} \mathrm{Acad}$ Dermatol 1990;23:638-40.

22 Grignon DJ, Shum DT, Bruckschwaiger O. Transitional cel carcinoma in the Muir-Torre syndrome. F Urol 1987; 138:406-8

23 Lynch HT, Smyrk TC, Lynch PM, et al. Adenocarcinoma of the small bowel in Lynch syndrome II. Cance 1989;64:2178-83.

24 Lynch HT, Ens JA, Lynch JF. The Lynch syndrome II and urological malignancies. $\mathcal{J}$ Urol 1990;143:24-8.

25 Watson P, Lynch HT. Extracolonic cancer in hereditar nonpolyposis colorectal cancer. Cancer 1993;71:677-85. 
26 Office of Population Censuses and Surveys. Cancer survival, 1979-81 registrations. London: HMSO, 1986.

27 Symonds DA, Vickery AL. Mucinous carcinoma of the colon and rectum. Cancer 1976;37:1891-900.

28 Phillips RSK, Hittinger R, Blesovsky L, Fry JS, Fielding LP. Large bowel cancer: surgical pathology and its rela-
Lithel LP. Large bowel cancer: surgical pathology and
tionship to survival. $B r f$ Surg 1984;71:604-10.

29 Mecklin J-P, Sipponen P, Järvinen HJ. Histopathology of colorectal carcinomas and adenomas in cancer family syndrome. Dis Colon Rectum 1986;29:849-53.

30 Mecklin J-P, Järvinen HJ. Clinical features of colorectal carcinoma in cancer family syndrome. Dis Colon Rectum 1986;29:160-4

31 Albano WA, Recabaren JA, Lynch HT, et al. Natural history of hereditary cancer of the breast and colon. Cancer 1982;50:360-3.

32 Lynch HT, Lanspa S, Smyrk T, Boman B, Watson P, Lynch $\mathrm{J}$. Hereditary nonpolyposis colorectal cancer (Lynch syn- dromes I and II): genetics, pathology, natural history, and cancer control. Part 1. Cancer Genet Cytogenet 1991;53:143-60

33 Fitzgibbons RJ, Lynch HT, Stanislav GV, et al. Recognition and treatment of patients with hereditary nonpolyposis colon cancer (Lynch syndromes I and II). Ann Surg colon cancer (Lynch syndromes I and II). Ann Surg

34 Houlston RS, Murday V, Harocopos C, Williams CB, Slack $\mathrm{J}$. Screening and genetic counselling for relatives of patients with colorectal cancer in a family screening clinic. BMF 1990;301:366-8.

35 Lynch HT, Smyrk TC, Lanspa SJ, Jenkins JX, Cavalieri J, Lynch JF. Cancer control problems in the Lynch syndromes. Dis Colon Rectum 1993;36:254-60.

36 Vasen HF, Mecklin J-P, Watson P, et al. Surveillance in hereditary nonpolyposis colorectal cancer: an international cooperative study of 165 families. Dis Colon Rectum 1993;36:1-4. 